American Journal of Pharmaceutical Education 2016; 80 (6) Article 104.

\title{
RESEARCH
}

\section{Using Text Analytics of AJPE Article Titles to Reveal Trends In Pharmacy Education Over the Past Two Decades}

\author{
Farnoush Pedrami PharmD, Pamela Asenso PharmD, and Sachin Devi, PhD, BPharm \\ Lake Erie College of Osteopathic Medicine, School of Pharmacy, Bradenton, Florida \\ Submitted June 25, 2015; accepted October 14, 2015; published August 25, 2016.
}

Objective. To identify trends in pharmacy education during last two decades using text mining.

Methods. Articles published in the American Journal of Pharmaceutical Education (AJPE) in the past two decades were compiled in a database. Custom text analytics software was written using Visual Basic programming language in the Visual Basic for Applications (VBA) editor of Excel 2007. Frequency of words appearing in article titles was calculated using the custom VBA software. Data were analyzed to identify the emerging trends in pharmacy education.

Results. Three educational trends emerged: active learning, interprofessional, and cultural competency.

Conclusion. The text analytics program successfully identified trends in article topics and may be a useful compass to predict the future course of pharmacy education.

Keywords: AJPE, text analytics, pharmacy education

\section{INTRODUCTION}

In the past century, the pharmacist's role was product driven. Pharmacists played a central role in manufacturing and dispensing medications. The end of the twentieth century witnessed an evolving role for pharmacists, culminating in the past two decades' shift from the product to the patient. ${ }^{1}$ Over the course of these two decades, the pharmacist's role expanded to include primary care and disease state management such as initiating drug therapy, finding potential drug interactions, and counseling patients about the proper use of medications. ${ }^{2}$ The pharmacist is an integral part of the health care team and collaborates with other health care professionals to help patients manage their medications. ${ }^{3}$ This evolving patient-centered role necessitated additional training for pharmacy professionals in the areas of critical thinking, decision making, and communication skills. With the change came the need to reform pharmacy education that would enable students to not only gain knowledge but also apply and transmit that knowledge.

After much debate, the baccalaureate degree in pharmacy was phased out, and the doctor of pharmacy (PharmD) became the entry-level degree to practice pharmacy. In 1997, the Accreditation Council for Pharmacy Education (ACPE) adopted Accreditation Standards and Guidelines for the Professional Program in Pharmacy Leading to the Doctor of Pharmacy Degree. ${ }^{4}$ In academic year 2004-2005,

Corresponding Author: Sachin Devi, 5000 Lakewood Ranch Blvd., LECOM School of Pharmacy, Bradenton, FL, 34203. Tel: 941-782-5941. E-mail: sdevi@lecom.edu the last student obtained a baccalaureate degree in pharmacy. Thereafter, pharmacy colleges and schools around the country developed new curricula based on cutting edge research in pharmaceutical, social, and clinical sciences. Introductory pharmacy practice experiences (IPPEs) were introduced as a component of the PharmD curriculum. The new curriculum was designed to ensure the development of competent and confident students who could contribute to patient care in collaboration with other health care providers. Scholarly articles were published to document curricular changes made by pharmacy schools and their impact on pharmacy education. ${ }^{5-9}$ We hypothesized that analyzing titles of published scholarly articles would provide insights into trends in pharmacy education and may help guide future direction of pharmacy education.

The American Journal of Pharmaceutical Education (AJPE) is the official scholarly publication of the American Association of Colleges of Pharmacy (AACP). Since its inception in 1937, it has only published material related to pharmaceutical education and, therefore, reflects the changing trends in that field. The advances of pharmaceutical education in the United States and internationally is well documented in AJPE, which serves as an archive of such advances. ${ }^{10}$ A title is an important component of any journal article. An article title is intended to describe the content of the article. In other words, the article title is the reflection of the main theme of the article. We hypothesized that analyzing titles of all scholarly articles published in AJPE would reveal trends in pharmacy education. 


\section{American Journal of Pharmaceutical Education 2016; 80 (6) Article 104.}

A challenge in identifying any trend is minimizing human bias, if not completely eliminating it. Text mining, also referred to as text analytics, offers a solution to this problem by allowing researchers to digitally extract and analyze vast amounts of published text at a rapid ratee. ${ }^{11}$ Algorithms are written to extract meaningful patterns from the published text, which helps to eliminate human bias. Therefore, the objective of this study was to identify trends in pharmacy education during the last two decades using text mining. The 2-decade timeline was chosen for this study because pharmacy education underwent immense transformation during this period.

\section{METHODS}

Titles of all the AJPE articles published from 19952014 were retrieved from the AJPE website ${ }^{12}$ and parsed into comma separated values (csv) file format. For further data analysis, the software was developed as a set of Excel macros, using Excel Visual Basic for Applications (VBA). Titles of all AJPE articles indexed in Pubmed were saved using search query "Am J Pharm Educ." [Journal]. As of Feb 2, 2015, 1990 AJPE articles were indexed in Pubmed. A summary of the articles indexed in Pubmed were downloaded using Flink. ${ }^{14}$ The summary included information about each article such as title, publication date, and authors. The number of AJPE articles indexed in Pubmed were plotted against the year of publication (data not shown). Not all AJPE articles were indexed by Pubmed. Therefore, titles of all the AJPE articles that were published in the past two decades (1995-2014) were retrieved from the AJPE website. ${ }^{12}$ In total, 3220 articles were published in AJPE over the course of the two decades.

Custom programming structure was designed to exploit the Microsoft Excel 2007 platform. Backend programming procedures were customized using Visual Basic in the Visual Basic for Applications editor of Excel 2007. Furthermore, front-end programming, also known as "front-loader" program where custom programming command can be initiated with icons, were developed with Visual Basic 6.0 (VB6). This custom software, developed as a set of Excel macros, calculates frequency of the words in titles of AJPE articles. For the purpose of writing the software algorithm, "word" was defined as the set of letters present between two spaces.

\section{RESULTS}

Table 1 lists the top 25 words that most frequently appeared in AJPE article published between 1995 and 2014. Prepositions, conjunctions, articles, etc., hold spots in this list. In a structured sentence, such words act as bridges and provide clues to determine the relationship between other words used in the sentence. However, they do not
Table 1. Frequently Appearing Top 25 Words in the Titles of AJPE Articles Published between 1995-2004

\begin{tabular}{rlcclc}
\hline Sr & \multicolumn{1}{c}{ Word } & Frequency & Sr & \multicolumn{1}{c}{ Word } & Frequency \\
\hline 1 & of & 1976 & 14 & Education & 184 \\
2 & the & 1202 & 15 & Learning & 183 \\
3 & Pharmacy & 1075 & 16 & Course & 157 \\
4 & and & 1054 & 17 & Council & 142 \\
5 & a & 929 & 18 & Development & 140 \\
6 & in & 842 & 19 & Pharmaceutical & 139 \\
7 & to & 540 & 20 & Academic & 134 \\
8 & for & 531 & 21 & Faculty & 133 \\
9 & An & 330 & 22 & Teaching & 128 \\
10 & on & 251 & 23 & Students & 120 \\
11 & Student & 224 & 24 & Health & 119 \\
12 & Report & 221 & 25 & Assessment & 119 \\
13 & Practice & 213 & & & \\
\hline
\end{tabular}

$\mathrm{Sr}=$ serial number

provide meaningful information if listed as a single word as presented in Table 1. Therefore, a second software algorithm was written to ignore common articles, prepositions, and conjunctions. Table 2 provides the resulting list of top 25 words that most frequently appeared in the titles of AJPE articles published between 1995 and 2014.

The word, "pharmacy" appeared most frequently in AJPE articles titles. Similarly, the words "students," "practice," and "education" made the list of the top 25 frequently appearing words in AJPE titles. These data indicate the main emphasis of scholarly articles was around the themes students, practice, and education. The words "AACP," "report," and "using" made the list of top 25 frequently appearing words in AJPE titles. These results indicate that many AACP reports were also published in AJPE.

Table 2. Frequently Appearing Top 25 Words $^{\mathrm{a}}$ in Titles of AJPE Articles Published between 1995-2004

\begin{tabular}{rlrllc}
\hline Sr & \multicolumn{1}{c}{ Word } & Frequency & Sr & \multicolumn{1}{c}{ Word } & Frequency \\
\hline 1 & Pharmacy & 1075 & 14 & Students & 120 \\
2 & Student & 224 & 15 & Health & 119 \\
3 & Report & 221 & 16 & Assessment & 119 \\
4 & Practice & 213 & 17 & July & 117 \\
5 & Education & 184 & 18 & Minutes & 112 \\
6 & Learning & 183 & 19 & Clinical & 110 \\
7 & Course & 157 & 20 & Advanced & 107 \\
8 & Council & 142 & 21 & Care & 106 \\
9 & Development & 140 & 22 & Using & 104 \\
10 & Pharmaceutical & 139 & 23 & Students & 104 \\
11 & Academic & 134 & 24 & Colleges & 99 \\
12 & Faculty & 133 & 25 & AACP & 97 \\
13 & Teaching & 128 & & & \\
\hline
\end{tabular}

${ }^{a}$ Ignoring prepositions, articles, and conjunctions $\mathrm{Sr}=$ serial number 


\section{American Journal of Pharmaceutical Education 2016; 80 (6) Article 104.}

The list of most frequently occurring top 25 words (Table 2) provides the information on the words (areas or topics) that received greatest emphasis in the past two decades. However, it does not identify trends in pharmacy education in the past two decades. Therefore, frequency of most frequently occurring top 25 words was calculated for each year over the past two decades. Tables 3 and 4 illustrate frequency distribution on annual basis over the past two decades. Correlation coefficient was calculated for each word to gauge the trend. Positive correlation coefficient value indicates uptrend whereas negative correlation coefficient value indicates downtrend. As indicated by positive correlation coefficient values, use of words "pharmacy," "student," and "practice" gradually increased over the period (uptrend). On the other hand, the number of reports and minutes declined as indicated by negative correlation coefficient (downtrend).

Tables 3 and 4 provide insights into the trend in distribution frequency of most frequently occurring top 25 words. However, they do not identify emerging trends in pharmacy education in the past two decades. To identify emerging trends, frequency of all the words appeared in AJPE article titles during the first decade (1995-2004, referred to as "previous decade" in this manuscript) and the second decade (2005-2014, referred to as "last decade" in this manuscript) was calculated. Then, percentage change in the frequency of every word in the last decade was calculated using the frequency of the same word in the previous decade as baseline. Although percentage change in the frequency of each word was calculated, only the top 25 words that demonstrated maximum percentage in frequency increase are listed in Table 5. These data indicated that the use of the word "active learning" increased by $2400 \%$ in the last decade compared to the previous decade. Similarly, the use of the word "interprofessional" increased by $2100 \%$ in the last decade compared to the previous decade. After detailed analysis of the data presented in Table 5, three main trends in pharmacy education emerged: (1) active-learning, (2) interprofessional, and (3) cultural competency. Our data also indicate that more emphasis was given to scholarly activities and residencies in the last decade (2005-2014) compared to the previous decade (19952004).

\section{DISCUSSION}

In the digital age, scholarly articles are published at a rapid rate. However, the tremendous volume of text data presents a challenge to unearthing relationships between

Table 3. Frequency Distribution of Top 25 Words in AJPE Article Titles over the Previous Decade (1995-2004)

\begin{tabular}{lrrrrrrrrrr}
\hline Word & $\mathbf{1 9 9 5}$ & $\mathbf{1 9 9 6}$ & $\mathbf{1 9 9 7}$ & $\mathbf{1 9 9 8}$ & $\mathbf{1 9 9 9}$ & $\mathbf{2 0 0 0}$ & $\mathbf{2 0 0 1}$ & $\mathbf{2 0 0 2}$ & $\mathbf{2 0 0 3}$ & $\mathbf{2 0 0 4}$ \\
\hline Pharmacy & 21 & 22 & 22 & 14 & 22 & 29 & 17 & 38 & 37 & 56 \\
Student & 5 & 3 & 8 & 6 & 7 & 5 & 10 & 6 & 11 & 12 \\
Report & 14 & 14 & 16 & 15 & 11 & 14 & 13 & 13 & 6 & 14 \\
Practice & 4 & 7 & 6 & 5 & 5 & 3 & 1 & 6 & 7 & 12 \\
Education & 2 & 10 & 2 & 5 & 6 & 7 & 3 & 3 & 5 & 6 \\
Learning & 4 & 4 & 4 & 5 & 11 & 5 & 6 & 6 & 3 & 13 \\
Course & 1 & 2 & 2 & 8 & 4 & 4 & 6 & 2 & 2 & 8 \\
Council & 8 & 7 & 8 & 8 & 7 & 8 & 7 & 7 & 5 & 7 \\
Development & 3 & 3 & 8 & 7 & 9 & 11 & 7 & 6 & 7 & 6 \\
Pharmaceutical & 5 & 8 & 14 & 10 & 13 & 10 & 8 & 4 & 14 & 5 \\
Academic & 5 & 4 & 4 & 5 & 5 & 4 & 6 & 5 & 3 & 8 \\
Faculty & 5 & 1 & 5 & 1 & 0 & 0 & 5 & 4 & 8 & 1 \\
Teaching & 6 & 4 & 7 & 6 & 5 & 4 & 4 & 4 & 4 & 7 \\
Students & 1 & 0 & 4 & 3 & 4 & 7 & 5 & 2 & 3 & 6 \\
Health & 1 & 2 & 4 & 4 & 1 & 2 & 3 & 4 & 2 & 4 \\
Assessment & 2 & 5 & 5 & 3 & 3 & 5 & 3 & 6 & 3 & 5 \\
July & 7 & 6 & 5 & 5 & 5 & 5 & 5 & 5 & 4 & 5 \\
Minutes & 9 & 9 & 8 & 7 & 8 & 8 & 8 & 8 & 6 & 8 \\
Clinical & 7 & 0 & 4 & 8 & 4 & 3 & 1 & 3 & 6 & 4 \\
Advanced & 0 & 1 & 0 & 1 & 1 & 1 & 0 & 1 & 3 & 4 \\
Care & 4 & 5 & 4 & 7 & 3 & 4 & 3 & 3 & 7 & 5 \\
Using & 3 & 2 & 2 & 2 & 4 & 5 & 2 & 4 & 4 & 5 \\
Students' & 0 & 1 & 1 & 3 & 4 & 4 & 1 & 4 & 2 & 5 \\
Colleges & 4 & 4 & 0 & 2 & 2 & 2 & 1 & 4 & 2 & 6 \\
AACP & 5 & 4 & 7 & 5 & 5 & 6 & 5 & 7 & 4 & 3 \\
\hline
\end{tabular}


American Journal of Pharmaceutical Education 2016; 80 (6) Article 104.

Table 4. Frequency Distribution of Top 25 Words in AJPE Article Titles over the Past Decade (2005-2014)

\begin{tabular}{|c|c|c|c|c|c|c|c|c|c|c|c|}
\hline Word & 2005 & 2006 & 2007 & 2008 & 2009 & 2010 & 2011 & 2012 & 2013 & 2014 & $\mathbf{r}^{\mathrm{a}}$ \\
\hline Pharmacy & 41 & 50 & 53 & 78 & 63 & 92 & 103 & 107 & 112 & 98 & 0.94 \\
\hline Student & 12 & 10 & 5 & 6 & 9 & 17 & 21 & 15 & 26 & 30 & 0.78 \\
\hline Report & 12 & 10 & 12 & 8 & 7 & 8 & 7 & 9 & 11 & 7 & -0.74 \\
\hline Practice & 14 & 15 & 10 & 8 & 15 & 15 & 17 & 21 & 20 & 22 & 0.88 \\
\hline Education & 13 & 5 & 10 & 15 & 12 & 15 & 15 & 12 & 17 & 21 & 0.82 \\
\hline Learning & 7 & 13 & 9 & 6 & 13 & 13 & 16 & 11 & 20 & 14 & 0.78 \\
\hline Course & 1 & 8 & 5 & 7 & 15 & 15 & 16 & 18 & 17 & 16 & 0.84 \\
\hline Council & 7 & 8 & 8 & 7 & 6 & 4 & 9 & 7 & 8 & 6 & -0.23 \\
\hline Development & 7 & 5 & 4 & 4 & 4 & 5 & 11 & 13 & 8 & 12 & 0.36 \\
\hline Pharmaceutical & 4 & 5 & 4 & 3 & 1 & 3 & 8 & 6 & 11 & 3 & -0.44 \\
\hline Academic & 6 & 11 & 3 & 8 & 6 & 8 & 8 & 12 & 9 & 14 & 0.72 \\
\hline Faculty & 5 & 7 & 2 & 9 & 2 & 8 & 16 & 20 & 14 & 20 & 0.74 \\
\hline Teaching & 9 & 6 & 8 & 3 & 7 & 9 & 7 & 8 & 9 & 11 & 0.61 \\
\hline Students & 5 & 8 & 8 & 7 & 6 & 7 & 11 & 13 & 10 & 10 & 0.86 \\
\hline Health & 3 & 8 & 5 & 1 & 14 & 15 & 8 & 13 & 9 & 16 & 0.77 \\
\hline Assessment & 4 & 6 & 12 & 6 & 6 & 10 & 12 & 8 & 7 & 8 & 0.70 \\
\hline July & 4 & 7 & 8 & 5 & 7 & 5 & 9 & 7 & 6 & 7 & 0.41 \\
\hline Minutes & 8 & 5 & 8 & 5 & 7 & 0 & 0 & 0 & 0 & 0 & -0.84 \\
\hline Clinical & 1 & 4 & 5 & 8 & 1 & 9 & 14 & 10 & 8 & 10 & 0.54 \\
\hline Advanced & 7 & 13 & 4 & 6 & 11 & 13 & 8 & 14 & 8 & 11 & 0.85 \\
\hline Care & 5 & 3 & 3 & 2 & 5 & 11 & 8 & 5 & 14 & 5 & 0.42 \\
\hline Using & 2 & 7 & 4 & 10 & 6 & 7 & 13 & 5 & 7 & 10 & 0.74 \\
\hline Students' & 3 & 9 & 11 & 14 & 15 & 20 & 5 & 1 & 1 & 0 & 0.35 \\
\hline Colleges & 6 & 6 & 8 & 7 & 6 & 5 & 10 & 11 & 9 & 4 & 0.73 \\
\hline $\mathrm{AACP}$ & 2 & 3 & 6 & 7 & 5 & 4 & 5 & 6 & 4 & 4 & -0.16 \\
\hline
\end{tabular}

${ }^{a} \mathrm{r}$ denotes correlation coefficient calculated for two decades

scholarly articles and identifying long-term or emerging trends. Text analytics is a branch of computer science that assists in identifying meaningful relationships within the large volume of text. Since many changes in pharmacy profession have occurred in the last two decades, VBA software was written to identify the trends in the pharmacy education over the period (1995-2014).

Assumptions were made to write the text analytics algorithm. The first assumption was that authors included the most prominent ideas or themes in the article title. For example, if central theme in AJPE article is "active learning" then we assumed the term active learning would be included in the title of article. Thus, the algorithm was written to analyze the text in article titles to identify main themes. The second assumption was that the higher the frequency, the higher the importance of the word. The list of the words that were most frequently used in the titles of the AJPE articles published in the past two decades essentially provides the list of central themes of articles published in AJPE during this time period. Our data indicates that the scholarly activity in pharmacy education was centered around students, learning, faculty, and teaching, with additional emphasis on clinical, pharmaceutical, course, and development. This data-driven information enables identifying themes that received higher emphasis, which in turn, can guide future direction of pharmacy education.

Based on positive values of correlation coefficient, themes such as pharmacy, students, and learning increased over the two decades. On the other hand, negative values of correlation coefficient indicate that publications around themes such as "reports" and "minutes" decreased over that time period. These data indicate that AJPE put more emphasis on publishing articles in the area of pharmacy education and less emphasis on publishing reports and minutes. Further, data analysis reveals trends in prominent themes in pharmacy education during these two decades. However, to know emerging trends in pharmacy education, percentage increase in the frequency of the words in the last decade from the previous decade was calculated. The higher the percentage increase from the previous decade, the bigger the emerging trend. After calculating percentage increase for all words, three major trends emerged: 1) active learning 2) interprofessional, and 3) cultural competency. A literature search corroborated findings of text analytics software algorithm. Stewart et al developed a survey instrument to assess activelearning processes used in US pharmacy education. ${ }^{14}$ In line with our findings, Stewart et al noted increased use of 


\section{American Journal of Pharmaceutical Education 2016; 80 (6) Article 104.}

Table 5. Top 25 Words whose Frequency Increased in the Past Decade (2005-2014) Compared with the Previous Decade (1995-2004)

\begin{tabular}{|c|c|c|c|c|}
\hline Sr & Word & $\begin{array}{l}\text { Frequency } \\
1995-2004\end{array}$ & $\begin{array}{l}\text { Frequency } \\
2005-2014\end{array}$ & $\%$ change \\
\hline 1 & Active Learning & 1 & 24 & 2400 \\
\hline 2 & Interprofessional & 2 & 42 & 2100 \\
\hline 3 & Competency & 1 & 21 & 2100 \\
\hline 4 & Students' & 3 & 59 & 1967 \\
\hline 5 & Cultural & 1 & 18 & 1800 \\
\hline 6 & Therapy & 1 & 16 & 1600 \\
\hline 7 & US & 3 & 42 & 1400 \\
\hline 8 & Members & 1 & 12 & 1200 \\
\hline 9 & Delegates, & 1 & 11 & 1100 \\
\hline 10 & Standing & 1 & 11 & 1100 \\
\hline 11 & Recommendations & 1 & 11 & 1100 \\
\hline 12 & Improve & 4 & 41 & 1025 \\
\hline 13 & Ability & 1 & 10 & 1000 \\
\hline 14 & Project & 1 & 10 & 1000 \\
\hline 15 & Work & 1 & 9 & 900 \\
\hline 16 & Scholarly & 1 & 9 & 900 \\
\hline 17 & Standards & 1 & 9 & 900 \\
\hline 18 & Residency & 2 & 17 & 850 \\
\hline 19 & Guide & 1 & 8 & 800 \\
\hline 20 & Time & 1 & 8 & 800 \\
\hline 21 & Achievement & 1 & 8 & 800 \\
\hline 22 & Sessions, & 1 & 8 & 800 \\
\hline 23 & Perspective & 1 & 8 & 800 \\
\hline 24 & Electronic & 1 & 8 & 800 \\
\hline 25 & Healthcare & 1 & 8 & 800 \\
\hline
\end{tabular}

active-learning techniques in the US pharmacy schools. The term "interprofessional education" started to take root in 2003. The Institute of Medicine's report Health Professions Education: A Bridge to Quality emphasized need for educational programs in an interdisciplinary team. ${ }^{15}$ In 2013, Brazeau acknowledged integration of interprofessional education in course work, experiential programs, laboratories, etc., and argued that more interprofessional education is needed in US pharmacy curriculum. ${ }^{16}$ In 2006, ACPE included cultural competence in its accreditation standards. ${ }^{4}$ Onyoni et al documented evidence that US pharmacy schools began to include cultural competency in the curriculum. ${ }^{17}$

Analyzing AJPE titles is not the only method to gauge the emerging trends in pharmacy education. Additional studies are needed to analyze scholarly articles related to pharmacy education in other peer-reviewed journals. Additionally, one can gauge emerging trends in pharmacy education by analyzing posters presented during AACP's annual meeting. There are also limitations to text analytics programs, which treat words as datasets. That is, they isolate words to group and count them. However, text analytics programs cannot understand the meaning of words in the research context. Therefore, a human mind is needed to analyze the data. For example, the word "July" appeared several times in the list. Text analytics programs cannot understand that this word is unrelated or less significant in the context of our research topic of emerging trends pharmacy education. Therefore, additional studies are needed with natural language processing technology to determine contextual relationships.

\section{CONCLUSION}

Using appropriate assumptions and text analytics algorithms, an analysis of scholarly articles titles published in AJPE identified active learning, interprofessional, and cultural competency as major emerging trends in pharmacy education.

\section{ACKNOWLEDGMENT}

We would like to thank Dr. Mark Best from Lake Erie College of Osteopathic Medicine for his valuable feedback on this manuscript.

\section{REFERENCES}

1. Toklu HZ, Hussain A. The changing face of pharmacy practice and the need for a new model of pharmacy education. $J$ Young Pharm. 2013;5(2):38-40.

2. Abramowitz PW. The evolution and metamorphosis of the pharmacy practice model. Am J Health-Syst Pharm. 2009;66(16):1437-1446.

3. DeBenedette V. Pharmacy education: change is the only constant. Drug Topics. 2007;151(6):38.

4. Accreditation standards and guidelines for the professional program in pharmacy leading to the doctor of pharmacy degree. Adopted January 15, 2006. Accreditation Council for Pharmacy Education. https://www. acpe-accredit.org/pdf/ACPE_Revised_PharmD_Standards_Adopted_ Jan152006.pdf. Accessed April 8, 2015

5. Wuller WR, Luer MS. A sequence of introductory pharmacy practice experiences to address the new standards for experiential learning. Am J Pharm Educ. 2008;72(4):Article 73.

6. Cox CE, Lindblad AJ. A collaborative approach to improving and expanding an experiential education program. Am J Pharm Educ. 2012;76(3):Article 53.

7. Warholak TL, Noureldin M, West D, Holdford D. Faculty perceptions of the Educating Pharmacy Students to Improve Quality (EPIQ) program. Am J Pharm Educ. 2011;75(8):Article 163.

8. Nemire RE, Meyer SM. Educating students for practice: educational outcomes and community experience. Am J Pharm Educ. 2006;70(1): Article 20.

9. Stewart AL, Buckner IS, Wildfong PL. A shared assignment to integrate pharmaceutics and pharmacy practice course concepts. Am J Pharm Educ. 2011;75(3):Article 44.

10. DiPiro JT. AJPE: the voice of pharmacy education for 75 years. Am J Pharm Educ. 2011;75(1):Article 12.

11. Romero C, Ventura S. Data mining in education. Wiley Interdisciplinary Reviews: Data Mining and Knowledge Discovery. 2013;3(1): 12-27. 


\section{American Journal of Pharmaceutical Education 2016; 80 (6) Article 104.}

12. http://www.ajpe.org/loi/ajpe. Accessed March 6, 2015.

13. FLink: Frequency weighted links [Internet]. Bethesda (MD): National Library of Medicine (US), National Center for Biotechnology Information. 2010-[cited 201502 05]. http:// ncbi.nlm.nih.gov/Structure/flink/flink.cgi. Accessed February 2, 2015.

14. Stewart DW, Brown SD, Clavier CW, Wyatt J. Active-learning processes used in US pharmacy education. Am J Pharm Educ. 2011;75(4):Article 68.
15. Griener AC, Knebel E. Health Professions Education: A Bridge to Quality. Washington, DC: The National Academies Press; 2003. http://www.nap.edu/catalog/10681/health-professions-education-abridge-to-quality. Accessed August 28, 2015.

16. Brazeau GA. Interprofessional education: more is needed. $A m$ J Pharm Educ. 2013;77(9):Article 184.

17. Onyoni EM, Ives TJ. Assessing implementation of cultural competency content in the curricula of colleges of pharmacy in the United States and Canada. Am J Pharm Educ. 2007;71(2):Article 24. 